\title{
New class of agents for treatment of hypertension: focus on direct renin inhibition
}

\author{
This article was published in the following Dove Press journal: \\ Vascular Health and Risk Management \\ 30 September 2010 \\ Number of times this article has been viewed
}

\author{
Roberto Fogari \\ Annalisa Zoppi \\ Department of Internal Medicine and \\ Therapeutics, University of Pavia, Italy
}

Correspondence: Roberto Fogari Clinica Medica II Dipartimento di Medicina Interna, Piazza Golgi 19, 27I00 Pavia, Italy

Tel +390382526217

Fax +390382526259

Email r.fogari@unipv.it

\begin{abstract}
Aliskiren, the first orally active direct renin inhibitor, is an effective antihypertensive drug with distinctive characteristics, including good blockade of the renin-angiotensin system, a prolonged duration of action, pharmacologic effects that persist after drug discontinuation, and favorable tolerability comparable with placebo. The blood pressure-lowering effect of aliskiren monotherapy is similar, if not superior, to that of other first-line antihypertensive agents, and is greatly enhanced when aliskiren is combined with various other antihypertensive medications, without any adverse drug interactions. Aliskiren is also an effective and well tolerated therapy in special populations, including diabetic, obese, and elderly hypertensives. Beyond its blood pressure-lowering efficacy, results from experimental and clinical trials suggest that aliskiren has positive effects on markers of cardiovascular and renal damage. The ASPIRE (Aliskiren Study in Post-MI patients to Reduce rEmodelling) HIGHER clinical trials program is further assessing whether the promising pharmacologic properties of aliskiren translate into reduced risk of adverse cardiovascular and renal outcomes.
\end{abstract}

Keywords: aliskiren, renin inhibitors, hypertension, treatment

\section{Introduction}

The renin-angiotensin-aldosterone system (RAAS) plays a pivotal role in the homeostatic regulation of blood pressure (BP), fluid electrolytic balance, tissue perfusion, and vascular growth. ${ }^{1}$ Renin catalyzes the cleavage of angiotensinogen, producing the decapeptide, angiotensin I (Ang I). Angiotensin-converting enzyme (ACE) then catalyzes the conversion of Ang I to the octapeptide Ang II, the primary effector of the RAAS. The binding of Ang II to its Type 1 receptors, besides mediating its main biologic effects, including vasoconstriction, cell proliferation, hypertrophy, and aldosterone secretion, provides feedback inhibition of further renin release by the kidney (Figure 1). Additional components of the RAAS have been identified in the last decade, including bioactive Ang peptides, such as Ang III, Ang IV, and Ang-(1-7), the effects of which have not yet been fully elucidated for the cardiovascular and renal system. ${ }^{2}$ The discovery of the renin receptor has shed further light on the biology of the RAAS. Renin, simply considered until recently as the rate-limiting enzyme of RAAS activation, has also turned out to be the ligand for a protein known as the renin/prorenin receptor (RPR), which binds renin and prorenin about equally, regardless of their biologic activities. ${ }^{3}$ Prorenin, which represents $70 \%-90 \%$ of total circulating renin, when bound to the RPR, induces an increase in the catalytic efficiency of angiotensinogen conversion to Ang I, which contributes to local production of Ang II and its systemic levels, as well as binding of renin/prorenin 


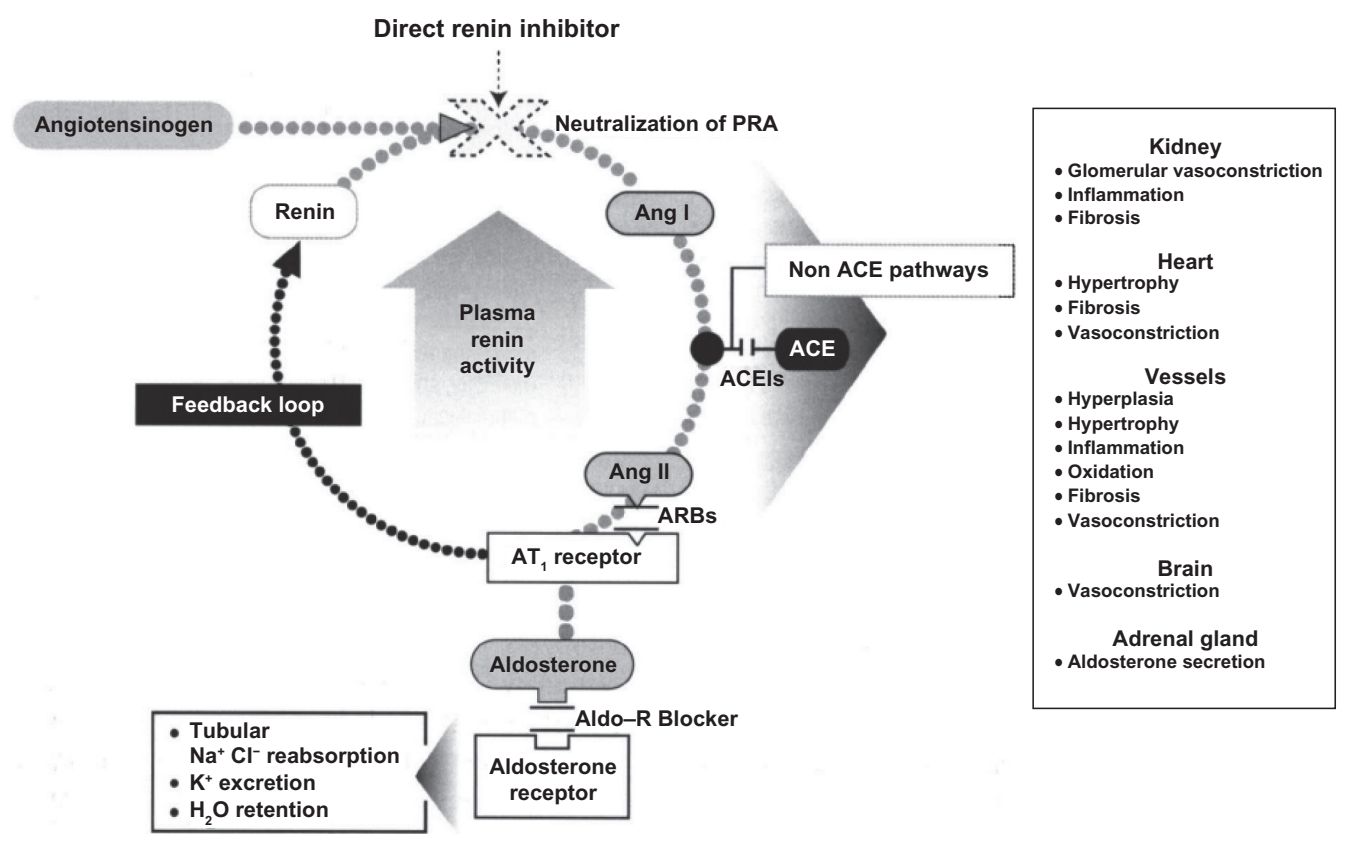

Figure I The renin-angiotensin-aldosterone system (RAAS) and antihypertensive drug classes affecting various sites of the RAAS.

Copyright $($ C 2008, Informa Healthcare. All rights reserved. Adapted with permission from Rashid H. Direct renin inhibition: an evaluation of the safety and tolerability of aliskiren. Curr Med Res Opin. 2008;24:2627-2637. ${ }^{9}$

Abbreviations: ACE, angiotensin-converting enzyme; ACEl, angiotensin-converting enzyme inhibitor; aldo, aldosterone; ARBs, angiotensin receptor blockers; Ang I, angiotensin I; Ang, angiotensin II.

to the RPR, exerting physiologic effects that are independent of Ang II, including activation of intracellular signal pathways, enhanced synthesis of DNA, and stimulation of the release of plasminogen activator inhibitor (PAI-1), collagen-1, fibronectin, and transforming growth factor beta- $1 .^{3}$

Pharmacologic blockade of the RAAS has proven to be an effective therapeutic strategy in the treatment of several cardiovascular disorders, including hypertension, heart failure, renal disease, and atherosclerosis. ${ }^{4}$ Until now, in clinical practice, the drug classes that provided RAAS inhibition included ACE inhibitors (ACEIs), which block the conversion of Ang I to Ang II, angiotensin receptor blockers (ARBs), which interfere with Ang II binding to its Type 1 receptors, and aldosterone antagonists, which inhibit aldosterone action via the mineralocorticoid receptor (MR) receptor. However, suppression of RAAS remains incomplete with these agents, due to the disruption of the negative feedback effect of Ang II on renin release, with a consequent increase in plasma renin activity (PRA) and reactive activation of the RAAS. ${ }^{5}$ Moreover, the increased Ang I levels seen with ACEIs can lead to "escape", because Ang I is converted to Ang II by nonACE pathways, mediated by chimase and chymotrypsin-like angiotensin-generating enzyme. Increased levels of Ang I and II could also lead to increased levels of biologically active Ang fragments. ${ }^{2}$ Therefore, direct renin inhibition may be a more optimal pharmacologic approach to RAAS inhibition by interrupting the system at its first regulated step. ${ }^{6}$

The purpose of this review is to update the different aspects of the antihypertensive potential of aliskiren, the first direct renin inhibitor available for clinical use. We will also discuss the role of aliskiren in the protection of target organs and the prevention of cardiovascular morbidity and mortality.

\section{Direct renin inhibitors and aliskiren}

The chemical development of renin inhibitors can be divided into three generations of compounds. ${ }^{7}$ First, there were the peptide analogs of angiotensinogen which block the enzymatic action of renin, second, the peptidomimetic agents that are dipeptide transition-state analog inhibitors of the active site, and third, the nonpeptide-like compounds, of which aliskiren is the most successful example. ${ }^{8}$ The first- and second-generation compounds were limited by poor metabolic stability and oral bioavailability, weak BPlowering efficacy, short duration of action, and high cost of synthesis. The third-generation compounds benefited from advances in crystallography and a structure-based approach to drug design, which led to the development of aliskiren. ${ }^{7,9}$ Molecular modeling was used to design and modify the aliskiren molecule, the structure of which was based on 
X-ray crystallographic analysis of the active site of renin. ${ }^{8}$ Aliskiren interacts with several binding pockets in distinct regions around the active site of renin, in particular, the renin subpocket (S3sp). ${ }^{8}$ Compared with peptidomimetic renin inhibitors, aliskiren has lower lipophilicity, which renders it more resistant to intestinal degradation. The hepatic extraction ratio $(12 \%)$ indicates a low rate of first-pass metabolism and the resulting bioavailability (about $2.6 \%$ ) is significantly greater than that of the earlier renin inhibitors. After administration of a single $150 \mathrm{mg}$ or $300 \mathrm{mg}$ dose of the drug, peak plasma concentration is reached within 2.5-3.0 hours, while steady-state plasma concentrations are reached within $7-8$ days..$^{10}$ About $90 \%$ of the absorbed dose of aliskiren is eliminated by the fecal route and less than $0.6 \%$ is recovered in the urine. The terminal half-life ranges between 23 and 40 hours, which makes it suitable for once-daily dosing. Pharmacokinetic studies have shown that there is no need for dose adjustment in patients with renal or hepatic disease or for elderly patients or patients with diabetes. ${ }^{11,12}$ Due to its lack of effect on cytochrome P450 isoenzyme activities, aliskiren has a low potential for drug interactions. ${ }^{9}$

\section{Effects of aliskiren on RAS components}

The different approach to renin-angiotensin system (RAS) blockade of aliskiren as compared with ACEIs and ARBs results in differing effects on RAAS components (Table 1). In clinical studies using aliskiren, a significant reduction of PRA ranging from $70 \%$ to $75 \%$ was observed. This contrasts with both ACEIs and ARBs, which increase PRA due to disruption of the negative feedback loop whereby Ang II suppresses renin release and stimulates a reactive rise in plasma renin concentrations (PRC). Aliskiren increases renin release by the same mechanisms and augments PRC. However, the enzymatic activity of the renin released is blocked by

Table I Changes in renin, plasma renin activity, plasma Ang I, plasma Ang II and tissue Ang II levels in response to antihypertensive drug classes affecting various sites of the RAAS

\begin{tabular}{llllll}
\hline Drug class & Renin & PRA & $\begin{array}{l}\text { Plasma } \\
\text { Ang I }\end{array}$ & $\begin{array}{l}\text { Plasma } \\
\text { Ang II }\end{array}$ & $\begin{array}{l}\text { Tissue } \\
\text { Ang II }\end{array}$ \\
\hline ACE I & $\uparrow \uparrow$ & $\uparrow \uparrow$ & $\uparrow \uparrow$ & $=\downarrow$ & $=\downarrow$ \\
ARB & $\uparrow \uparrow$ & $\uparrow \uparrow$ & $\uparrow \uparrow$ & $\uparrow \uparrow$ & $\uparrow \uparrow$ \\
Diuretics & $\uparrow \uparrow$ & $\uparrow$ & $\uparrow$ & $\uparrow$ & $\uparrow$ \\
Renin inhibitor & $\uparrow \uparrow$ & $\downarrow \downarrow$ & $\downarrow \downarrow$ & $\downarrow \downarrow$ & $?$ \\
ARB + Renin inhibitor & $\uparrow \uparrow \uparrow \uparrow$ & $\downarrow$ & $=$ & $=$ & $?$ \\
\hline
\end{tabular}

Abbreviations: $\uparrow$, Increase; $\downarrow$, decreased; =, unchanged; ACE I, angiotensin converting enzyme inhibitors; $A R B$, angiotensin type I receptor blocker; DRI, direct renin inhibitor. aliskiren and PRA is reduced. Concerns have been expressed about the high aliskiren-induced reactive increase in plasma renin and prorenin, because even though aliskiren may lack enzymatic activity, it can still bind to the RPR, a signaling pathway of as yet unknown significance. ${ }^{13}$ An important question is whether aliskiren inhibits the enzymatic effects of renin/prorenin when they are bound to the RPR. Available information suggests that it does. Although the drug does not block direct intracellular effects, Feldman et al reported that aliskiren downregulates RPR expression in diabetic transgenic rats. ${ }^{14}$ In humans we have no direct evidence of this. However, there are no data from clinical trials done in 14,000 patients to indicate that the rise in PRC in any way limits the ability of aliskiren to inhibit PRA or lower BP. Besides, even if more renin is released in response to aliskiren than with RAAS blockers, there is no evidence that this overcomes the enzymatic inhibition of renin. Given that all RAAS blockers, as well as other antihypertensive drugs, including diuretics and calcium channel blockers (CCBs), increase PRC levels yet have proved effective in reducing long-term cardiovascular endpoints, it seems unlikely that increases in PRC resulting from aliskiren administration could act as an agonist at the RPR with potentially deleterious consequences. ${ }^{15}$ Furthermore, recent literature also indicates that large increase in PRC levels with aliskiren may be in part artifactual, because commercial PRC assays overestimate the renin concentration in plasma samples containing a direct renin inhibitor. ${ }^{16}$

\section{Aliskiren in hypertension}

Clinical trials involving more than 14,000 patients have shown that aliskiren, alone or in combination with other antihypertensive agents, provides effective BP reduction with a good safety and tolerability profile.

\section{Monotherapy}

The first demonstration of the antihypertensive efficacy of aliskiren monotherapy was seen in 2001 in a group of mild to moderate hypertensives treated with aliskiren $75 \mathrm{mg}$ or $150 \mathrm{mg}$ for two weeks. ${ }^{17}$ Clinic and ambulatory BP values were significantly reduced by aliskiren without important adverse events. Following this success, a dose-finding study was conducted in 226 patients with mild to moderate hypertension who were randomly assigned to receive aliskiren $37.5 \mathrm{mg}$, $75 \mathrm{mg}, 150 \mathrm{mg}$, or $300 \mathrm{mg}$, or losartan $100 \mathrm{mg}$ once daily for four weeks. ${ }^{18}$ Dose-dependent reductions in BP were observed, and the best 24-hour effect of aliskiren on ambulatory BP was demonstrated for the $300 \mathrm{mg}$ dose. 
After these two preliminary studies, the antihypertensive efficacy of aliskiren monotherapy has been further assessed in comparison with placebo and with other antihypertensive drugs.

\section{Comparisons with placebo}

In 2005, a placebo-controlled study was conducted in 518 hypertensive patients who were randomized to treatment with aliskiren at daily doses of $150 \mathrm{mg}, 300 \mathrm{mg}$, and $600 \mathrm{mg}$, or placebo, for eight weeks. ${ }^{19}$ All the aliskiren doses produced a significant reduction of BP compared with placebo, but the plateau of the dose-response curve was reached at $300 \mathrm{mg}$, and little or no additional BP reduction occurred with the $600 \mathrm{mg}$ dose. Another study versus placebo involved 540 Japanese hypertensives, who were treated with aliskiren $75 \mathrm{mg}, 150 \mathrm{mg}$, and $300 \mathrm{mg}$ once daily for eight weeks. Aliskiren was consistently superior to placebo in lowering BP, but again a significant dose-response effect was observed when aliskiren was increased from $150 \mathrm{mg} /$ day to $300 \mathrm{mg} /$ day. $^{20}$

The largest study of aliskiren versus placebo was performed by $\mathrm{Oh}$ et $\mathrm{al}^{21}$ who evaluated the effects of $150 \mathrm{mg}$, $300 \mathrm{mg}$, and $600 \mathrm{mg}$ of aliskiren in 672 patients for eight weeks, confirming the efficacy and the dose-response effect of the drug. In a subgroup of 216 patients who underwent ambulatory BP monitoring, the antihypertensive effect of aliskiren was sustained throughout the 24-hour dosing period, was similar during the day-time and night-time periods, and was maintained towards the end of the dosing period. The trough:peak ratios were 0.64 and 0.98 for the $150 \mathrm{mg}$ and $300 \mathrm{mg}$ dosages, respectively, which confirmed the long duration of action of aliskiren. The drug also provided smooth 24-hour BP control, as demonstrated by the mean smoothness index, which was 0.64 for the $150 \mathrm{mg}$ dose and 0.60 for the $300 \mathrm{mg}$ dose, compared with 0.17 for placebo.

The study by $\mathrm{Oh}$ et al was the first to demonstrate a persistent BP reduction effect after aliskiren withdrawal, an advantage that has been confirmed by other studies. ${ }^{22,23}$ In a controlled withdrawal study, patients who had received aliskiren for 11 months were randomized to continue treatment with aliskiren or placebo. After four weeks, BP values in the aliskiren-treated patients did not return to baseline, and PRA remained suppressed by about 50\%. ${ }^{22}$ Likewise, the results of an ambulatory BP monitoring study, designed to evaluate the antihypertensive efficacy of aliskiren following simulated nonadherence (missed dosing), demonstrated that aliskiren $300 \mathrm{mg}$ provided sustained BP-lowering effects beyond 24 hours that were longer-lasting than with irbesartan $300 \mathrm{mg}$ or ramipril (Figure 2). ${ }^{23}$ About $91 \%$ of the systolic BP-lowering effect of aliskiren was maintained in the 24 hours after a missed dose as compared with $73 \%$ for irbesartan and $64 \%$ for losartan. A sustained reduction in PRA following one or two missed doses (ie, for at least 72 hours after aliskiren dosing) was also observed. The long duration of action of aliskiren in part depends on its long elimination half-life and potent renin inhibition. Because even patients who are otherwise persistent with taking their antihypertensive therapy have been demonstrated to miss a dose of treatment occasionally, antihypertensive treatment that allows sustained BP-lowering effect beyond the 24-hour dosing interval may help to limit the effects of occasional poor adherence on BP control.

\section{Comparisons with other antihypertensive agents}

\section{Diuretics}

In a 2006 study, aliskiren 75-300 mg daily was consistently more effective than hydrochlorothiazide (HCTZ) $6.25 \mathrm{mg}$, $12.5 \mathrm{mg}$, and $25 \mathrm{mg}$ at reducing BP in hypertensive patients. ${ }^{24}$. The superiority of aliskiren was more evident at higher dosages. Another direct comparison study involving 1124 hypertensive patients confirmed that treatment with aliskiren $150 \mathrm{mg}$ force-titrated to $300 \mathrm{mg}$ daily reduced systolic/diastolic BP values by a significantly greater amount than HCTZ $12.5 \mathrm{mg}$ /day titrated to $25 \mathrm{mg}$ /day $(-20.3 / 14.2 \mathrm{mmHg}$ versus $-18.6 / 13.0 \mathrm{mmHg}, P<0.05) .{ }^{25}$ Responder and BP control rates were also higher among aliskiren-treated patients.

\section{ACE inhibitors}

Three large studies have compared aliskiren with ramipril. The first study included 837 hypertensive patients with diabetes treated either with aliskiren $150 \mathrm{mg}$, ramipril $5 \mathrm{mg}$, or aliskiren $150 \mathrm{mg}$ in combination with ramipril $5 \mathrm{mg} .{ }^{26}$ After four weeks, dosages were titrated to aliskiren $300 \mathrm{mg}$, ramipril $10 \mathrm{mg}$, and aliskiren $300 \mathrm{mg}+$ ramipril $10 \mathrm{mg}$ for a further four weeks. After eight weeks, aliskiren monotherapy produced a greater reduction in systolic BP compared with ramipril alone (14.7 versus $12.0 \mathrm{mmHg}, P<0.05$ ) and resulted in higher responder rates (73\% versus $66 \%$, $P<0.05)$. Interestingly, the incidence of cough was lower among patients receiving aliskiren (2.1\%) than among those receiving ramipril (4.7\%). Similar results were obtained in nondiabetic hypertensive patients. ${ }^{27}$ Specifically, 12 weeks of treatment with aliskiren 150-300 mg daily resulted in greater 

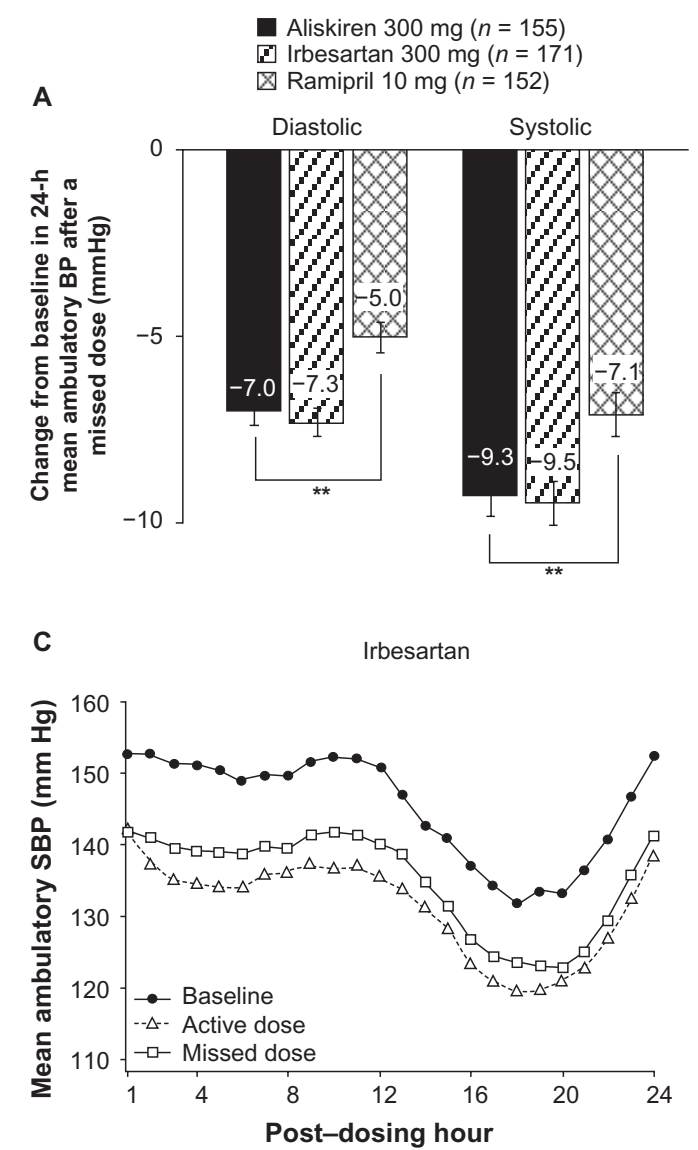

B

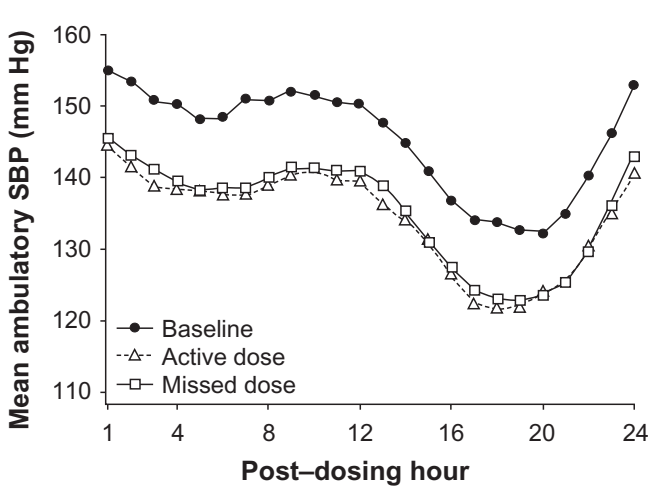

D

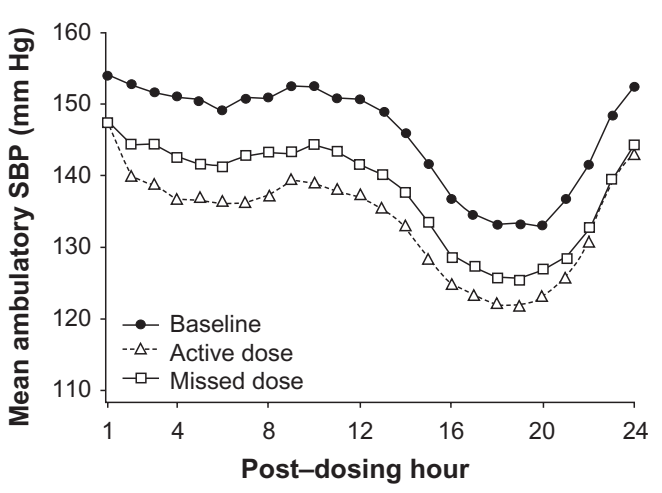

Figure 2 A) Changes from baseline in 24-hour mean ambulatory systolic and diastolic blood pressure (BP) after a missed dose of aliskiren $300 \mathrm{mg}$, irbesartan $300 \mathrm{mg}$ or ramipril $10 \mathrm{mg}$. Hourly change in 24-hour mean ambulatory systolic BP at baseline after a missed dose of treatment in patients receiving aliskiren $300 \mathrm{mg}$ (B), irbesartan $300 \mathrm{mg}(\mathbf{C})$ or ramipril $10 \mathrm{mg}(\mathbf{D})$.

$* * P<0.01$ for pair-wise comparison [by analysis of covariance (ANCOVA)]

Copyright (C) 2010, Nature Publishing Group, a subsidiary of Macmillan Publishers Ltd, and Nature America Inc. All rights reserved. Adapted with permission from Palatini P, Wung W, Shlyakhto E, Botha J, Bush C, Keefe DL. Maintenance of blood-pressure lowering effect following a missed dose of aliskiren, irbesartan or ramipril: Results of a randomized, double-blind study. J Hum Hypertens. 2010;24:93-103. ${ }^{23}$

reductions in both systolic $\mathrm{BP}(-14.0$ versus $-11.3 \mathrm{mmHg}$, $P=0.0027)$ and diastolic BP $(-11.3$ versus $-9.7 \mathrm{mmHg}$, $P=0.05)$ compared with ramipril 5-10 mg. Another demonstration of the greater antihypertensive efficacy of aliskiren compared with ramipril has been provided by the AGELESS (Aliskiren for Geriatric LowEring of SyStolic Hypertension) study, ${ }^{28}$ that compared these two drugs in 901 elderly patients ( $\geq 56$ years) with isolated systolic hypertension over 36 weeks of treatment. At 12 weeks, aliskiren monotherapy $150 \mathrm{mg}$ or $300 \mathrm{mg}$ produced significantly greater BP reduction than ramipril $5 \mathrm{mg}$ or $10 \mathrm{mg}(-14.0 / 5.1$ versus $-11.6 / 3.6 \mathrm{mmHg}, P=0.0241$ for systolic $\mathrm{BP}$ and $P=0.0037$ for diastolic BP). Furthermore, after 36 weeks, aliskiren-based therapy (with optional addition of HCTZ $12.5 \mathrm{mg}$ or $25 \mathrm{mg}$ and amlodipine $5 \mathrm{mg}$ or $10 \mathrm{mg}$ ) lowered BP more than ramipril-based therapy $(-20.8 / 8.2 \mathrm{mmHg}$ versus $-18.1 / 7.0 \mathrm{mmHg}, P=0.0747$ for systolic $\mathrm{BP}$ and $P<0.05$ for diastolic BP). In severe hypertension ( $>180 / 110 \mathrm{mmHg})$, aliskiren $300 \mathrm{mg}$ and lisinopril $40 \mathrm{mg}$ displayed similar antihypertensive efficacy, and the responder and BP control rates were similar for the two drugs. ${ }^{29}$

\section{Angiotensin receptor blockers}

After the preliminary study by Stanton ${ }^{17}$ showing comparable antihypertensive efficacy of aliskiren $150 \mathrm{mg}$ and $300 \mathrm{mg}$ and losartan $100 \mathrm{mg}$, Gradman observed that irbesartan $150 \mathrm{mg}$ was as effective as aliskiren $150 \mathrm{mg}$, but significantly less effective than aliskiren $300 \mathrm{mg} .{ }^{19}$ In 2007 , Oparil et $\mathrm{al}^{30}$ showed that aliskiren $300 \mathrm{mg}$ and valsartan $320 \mathrm{mg}$ provided similar reductions in both ambulatory and clinic BP (-13.0/9.0 mmHg with aliskiren versus -12.8/9.7 with valsartan). Similar results were also reported by Pool et al. ${ }^{31}$ More recently, the ALLAY (Aliskiren in Left Ventricular Hypertrophy) trial, ${ }^{32}$ conducted in 465 overweight 
hypertensives with left ventricular hypertrophy, apart from confirming similar BP-lowering efficacy of aliskiren $300 \mathrm{mg}$ and losartan $100 \mathrm{mg}$, also demonstrated that aliskiren was as effective as losartan in promoting regression of left ventricular mass.

\section{Combination therapy}

The majority of patients require two or more antihypertensive agents to achieve adequate BP control. Therefore, several studies have assessed the effects of aliskiren in combination with other antihypertensive drugs.

\section{Aliskiren combined with hydrochlorothiazide}

In a large factorial design study, the combination of aliskiren 75-300 mg with HCTZ 6.25-25 mg produced a significantly greater BP decrease than the component monotherapies. ${ }^{24} \mathrm{At}$ the highest combined dose of 300/25 mg, BP was reduced by a mean of $-21.2 / 14.3 \mathrm{mmHg}$. A reduced incidence of thiazide-induced hypokalemia was also observed with the combination, and the HCTZ-induced rise in PRA was neutralized by aliskiren. In another six-month study conducted in mild to moderate hypertensives uncontrolled by monotherapy with aliskiren or ramipril, addition of HCTZ to aliskiren provided significantly greater BP reductions than addition of HCTZ to ramipril (-17.9/13.2 versus $-15.2 / 12.0 \mathrm{mmHg}$, $P<0.05){ }^{27}$

\section{Aliskiren combined with amlodipine}

Adding aliskiren $150 \mathrm{mg}$ daily to the regimen of hypertensive patients who had inadequate BP control with amlodipine $5 \mathrm{mg}$ led to greater BP reduction $(-11.0 / 8.5 \mathrm{mmHg})$ compared with continuation of amlodipine $5 \mathrm{mg}(-5.0 / 4.8 \mathrm{mmHg}){ }^{33} \mathrm{The} \mathrm{BP}-$ lowering effect of the aliskiren-amlodipine combination was similar to that of amlodipine $10 \mathrm{mg}$. Higher responder and BP control rates were also observed with the combination therapy ( $64 \%$ and $43 \%$, respectively) than with amlodipine $5 \mathrm{mg}$ alone (45\% and $23 \%$ ). The incidence of ankle edema was markedly higher with amlodipine $5 \mathrm{mg}$ or $10 \mathrm{mg}(3.4 \%$ and $11.2 \%$, respectively) than with the aliskiren $150 \mathrm{mg}+$ amlodipine $5 \mathrm{mg}$ combination (2.1\%).

The effects of addition of aliskiren to amlodipine on ankle edema was specifically assessed in a recent study which demonstrated that the combination produced a significantly less marked increase in both ankle foot volume and pretibial subcutaneous tissue pressure (two objective measures of ankle edema) than amlodipine alone. ${ }^{34}$ In addition, the number of patients with clinically evident peripheral edema was lower among patients who received the combination. This suggests that direct renin inhibition partially counteracts the microcirculatory changes responsible for CCB-induced edema, which is similar to what is observed with ACEIs and ARBs.

The antihypertensive efficacy and tolerability of aliskirenamlodipine combination therapy was more recently confirmed by a long-term open study involving 556 mild to moderate hypertensives..$^{35}$ At the end of 12 months of treatment with aliskiren-amlodipine, a mean decrease of $-24.2 / 15.5 \mathrm{mmHg}$ in BP was found, with a rate of BP normalization of $74.3 \%$. Interestingly, in this study, the BP-lowering effect was more marked in the subgroup of patients with Stage II hypertension ( $\geq 160 / 100 \mathrm{mmHg}$ ), who showed a mean BP reduction of $-29.1 / 17.1 \mathrm{mmHg}$, demonstrating that the higher the baseline BP level, the greater the antihypertensive efficacy of the aliskiren-amlodipine combination.

\section{Aliskiren combined with an ACE inhibitor}

The efficacy of adding aliskiren $300 \mathrm{mg}$ to ramipril $10 \mathrm{mg}$ has been evaluated in hypertensive patients with diabetes. ${ }^{26} \mathrm{Com}-$ bination therapy provided a significant additional reduction in diastolic BP $(-12.8 \mathrm{mmHg})$ compared with each component monotherapy $(-10.7 \mathrm{mmHg}$ with ramipril and $-11.3 \mathrm{mmHg}$ with aliskiren). The combination also produced a greater decrease in systolic BP and led to a higher responder rate than ramipril monotherapy. Ambulatory BP measurements in a subset of 137 patients showed that the addition of aliskiren to ramipril resulted in greater reduction of mean 24-hour BP, thus improving BP control over 24 hours. ${ }^{36}$

\section{Aliskiren combined with an ARB}

In an eight-week study involving 1797 mild to moderate hypertensive patients, Oparil et al ${ }^{30}$ reported significantly greater BP reductions $(-17.2 / 12.2 \mathrm{mmHg})$ with an aliskiren $300 \mathrm{mg}+$ valsartan $320 \mathrm{mg}$ combination compared with aliskiren alone $(-13.0 / 9.0 \mathrm{mmHg})$ or valsartan alone $(-12.8 / 9.7 \mathrm{mmHg}$, both $P<0.0001$ versus the combination). Responder and BP control rates were also higher among recipients of combination therapy (66\% and 49\%, respectively) than among recipients of aliskiren (53\% and 37\%) and valsartan (55\% and 34\%) monotherapy. An excess of patients developed hyperkalemia with the combination, but in most cases this was transient and did not require drug discontinuation.

In an ambulatory BP monitoring study, an aliskirenvalsartan combination provided a significantly greater decrease in 24-hour ambulatory BP than each component monotherapy. ${ }^{37}$ The reductions in mean BP were $-14.4 / 10.3 \mathrm{mmHg}$ with the combination therapy, $-9.8 / 7.1 \mathrm{mmHg}$ with aliskiren, and $-10.1 / 7.1 \mathrm{mmHg}$ with valsartan. 


\section{Safety and tolerability}

In a pooled analysis that included data from more than 7000 hypertensive patients, the safety and tolerability profile of aliskiren monotherapy at doses of 75-600 mg daily was comparable with that of placebo and ARBs. ${ }^{38}$ The incidence of adverse events in the aliskiren $75 \mathrm{mg}(8.6 \%), 150 \mathrm{mg}(7.0 \%)$, $300 \mathrm{mg}(9.4 \%)$, and $600 \mathrm{mg}(11.8 \%)$ groups was similar to that observed in the placebo group (8.6\%). The most common adverse events were headache $(5.7 \%)$, nasopharyngitis (4.4\%), diarrhea $(2.6 \%)$, dizziness $(1.8 \%)$, and fatigue (1.6\%). Cough was substantially less frequent in patients treated with aliskiren compared with patients treated with ACEIs, and peripheral edema was substantially less frequent with aliskiren than with amlodipine. Serious adverse events in patients who were treated with aliskiren $75-600 \mathrm{mg}$ were rare in the clinical studies, occurring at rates no different from placebo $(0.3 \%-06 \%$ versus $0.6 \%){ }^{38}$

The tolerability profile of aliskiren was also good when the drug was combined with other antihypertensive medications. Hypokalemia related to diuretics, CCB-induced peripheral edema, and ACEI-related cough were less frequent when these drugs were combined with aliskiren. A numerically greater proportion of patients developed hyperkalemia when aliskiren was combined with ACEIs or ARBs, but this effect was transient and not associated with adverse events. Data from ASPIRE [Aliskiren Study in Post-MI patients to Reduce rEmodelling], recently presented at the American College of Cardiology Congress 2010), indicated that, in patients receiving aliskiren in addition to standard therapy with an ACEI or ARB following myocardial infarction, there was a higher rate of hyperkalemia (5.2\% versus $1.3 \%$ ), hypotension $(8.8 \%$ versus $4.5 \%)$, and kidney dysfunction $(2.4 \%$ versus $0.8 \%$ ) when compared with patients given standard therapy alone. ${ }^{39}$ These results suggest caution in the use of the combination of aliskiren with an RAAS blocker, at least in this subset of patients.

\section{Special populations Diabetic patients}

Diabetes is a common comorbidity in hypertensive patients and greatly increases the risk of cardiovascular and renal disease. ${ }^{40}$ Aliskiren has exhibited similar pharmacokinetics in diabetic patients and healthy volunteers. ${ }^{11}$ In the already cited paper of Uresin et $\mathrm{al}^{26}$ aliskiren $300 \mathrm{mg}$ monotherapy or aliskiren $300 \mathrm{mg}$ combined with ramipril $10 \mathrm{mg}$ was demonstrated to be more effective than ramipril alone in controlling $\mathrm{BP}$ in hypertensive patients with diabetes, without affecting glycemic control.
The antihypertensive efficacy of aliskiren at doses ranging from 150 to $300 \mathrm{mg}$ in hypertensive patients with diabetes was also demonstrated by a meta-analysis of 10 randomized, double-blind studies. ${ }^{41}$ The mean systolic/diastolic BP reductions of $-13.2 / 10.4 \mathrm{mmHg}$ with aliskiren $150 \mathrm{mg}$ and of $-14.8 / 12.2 \mathrm{mmHg}$ with aliskiren $300 \mathrm{mg}$ were similar to those observed in nondiabetic patients.

\section{Obese patients}

Obesity is another common comorbidity in hypertensive patients. ${ }^{42}$ Current hypertension treatment guidelines do not provide specific guidance for hypertension in the presence of obesity, although its peculiar pathophysiologic characteristics (volume expansion, increased cardiac output, and RAS activation) make thiazide diuretics and RAS inhibitors suitable treatment options. In a large multicenter study, ${ }^{43} 489$ obese hypertensives (body mass index $\geq 30 \mathrm{~kg} / \mathrm{m}^{2}$ ) who were nonresponders to treatment with HCTZ $25 \mathrm{mg}$ were treated with aliskiren $150 \mathrm{mg}$, irbesartan $300 \mathrm{mg}$, amlodipine $5 \mathrm{mg}$, or placebo in addition to HCTZ for four weeks, followed by eight weeks of double the initial dose of aliskiren, irbesartan, or amlodipine. After eight weeks of treatment, aliskiren-HCTZ lowered BP by $-15.8 / 11.9 \mathrm{mmHg}$, which was significantly $(P<0.0001)$ more than placebo-HCTZ $(-8.6 / 7.9 \mathrm{mmHg})$ and similar to irbesartan-HCTZ $(-15.4 / 11.3 \mathrm{mmHg})$ and amlodipine-HCTZ (-13.6/10.3 mmHg). Combination with aliskiren suppressed the increase in PRA caused by HCTZ, whereas irbesartan and amlodipine increased PRA further. All combinations were well tolerated, although there was a higher incidence of ankle edema in the amlodipine-treated patients $(11.1 \%$ versus $0.8 \%$ in the aliskiren group and $1.6 \%$ in the irbesartan group). The authors concluded that aliskiren was an effective and well tolerated therapeutic option for obese hypertensives who do not respond to first-line thiazide diuretic therapy. In a more recent 52-week study involving 396 obese hypertensives, Schmieder et a ${ }^{44}$ observed that aliskiren-based therapy lowered BP more effectively than HCTZ-based therapy $(-19.9 / 15.5$ versus $-17.5 / 9.1 \mathrm{mmHg})$ and was associated with a lower incidence of hypokalemia $(0.8 \%$ versus $17.9 \%, P<0.0001)$.

\section{Patients with metabolic syndrome}

Metabolic syndrome, a cluster of risk factors that increases overall cardiovascular risk, is also common in hypertensive patients. In a recent study involving 141 hypertensives with metabolic syndrome, aliskiren $300 \mathrm{mg}$ was more effective than irbesartan $300 \mathrm{mg}$ in reducing BP values $(-13.8 / 7.1 \mathrm{mmHg}$ versus $-5.8 / 2.8 \mathrm{mmHg}, P<0.0001){ }^{45}$ 
A greater proportion of patients achieved BP control to $<135 / 85 \mathrm{mmHg}$ with aliskiren $(29.2 \%$ versus $16.7 \%$, $P=0.019)$. In another comparative study conducted in 72 hypertensives with metabolic syndrome, aliskiren $300 \mathrm{mg}$, but not losartan $100 \mathrm{mg}$, significantly improved insulin sensitivity and fibrinolytic balance. ${ }^{46}$

\section{Elderly patients}

Differences in BP control with age have not been observed in aliskiren-treated patients. In a double-blind study conducted in 355 elderly hypertensives ( $\geq 65$ years) aliskiren at doses ranging from 75 to $300 \mathrm{mg}$ daily was as effective as lisinopril $10 \mathrm{mg}$ in lowering 24-hour ambulatory BP values. ${ }^{47}$ The results of the already cited AGELESS study ${ }^{28}$ demonstrated that aliskiren was more effective than ramipril in reducing BP in elderly patients with systolic hypertension and demonstrated a good tolerability profile. In a long-term comparative study of an aliskiren-based regimen with a HCTZ-based regimen, analysis of BP changes by age group showed that aliskiren provided significantly greater reductions in mean systolic BP (but not diastolic BP) in elderly ( $\geq 65$ years) and very elderly ( $\geq 75$ years) patients than in younger ones. ${ }^{44}$ Pooled data from seven clinical trials did not show a difference in adverse event profile for elderly patients compared with younger patients. ${ }^{38}$

\section{Aliskiren and target organ protection}

Some studies in animal models have suggested that aliskiren has an ability to protect against end organ damage. These data are derived mainly from studies of double-transgenic rats which express human genes for both renin and angiotensinogen. Untreated, these animals develop progressive hypertension with severe end organ damage and do not survive beyond eight weeks of life. When rendered diabetic by streptozotocin, they develop progressive renal disease, which is thought to be analogous to human diabetic nephropathy.

In humans, the target organ-protective effects of aliskiren are being investigated in ASPIRE HIGHER, the largest clinical trials program underway in the cardiorenal disease area, involving 14 randomized, double-blind studies including more than 35,000 patients with hypertension, diabetes, heart failure, renal dysfunction, and previous myocardial infarction. ${ }^{48}$

\section{Cardiac protection Experimental studies}

In a study conducted in double-transgenic rats, aliskiren improved systolic and diastolic BP, reduced cardiac hypertrophy, and left ventricular wall thickness, and decreased biomarkers of cardiac stress and failure, eg, atrial natriuretic peptide. ${ }^{49}$ Interestingly, in this study, whereas $100 \%$ of animals in the placebo group died by the ninth week of the experiment and $26 \%$ survived in the valsartan-treated group, $100 \%$ of the rats survived in the aliskiren-treated group. Similar results were obtained by Decherd et al in the same animal model. ${ }^{50}$

In another animal model (mice subjected to cardiac ischemia), aliskiren improved left ventricular systolic and diastolic function, and reduced cardiac hypertrophy and left ventricular dilatation at a dose that did not affect systemic BP. ${ }^{51}$ Furthermore, aliskiren suppressed ischemia-mediated activation of inflammation signaling pathways and reduced cellular markers of apoptosis.

\section{Clinical studies}

Four studies have been conducted in the area of heart failure and ventricular remodeling.

In a short-term, open study involving 27 patients, aliskiren $300 \mathrm{mg}$ was as effective and well tolerated as ramipril $10 \mathrm{mg}$ in patients with heart failure. ${ }^{52}$ Both drugs suppressed RAAS activation and reduced levels of B-type natriuretic peptide (BNP) to a similar extent (Figure 3).

The most important study that assessed the efficacy of aliskiren in patients with heart failure was the ALOFT (Aliskiren Observation of Heart Failure Treatment) trial. ${ }^{53}$ A total of 302 hypertensives who had stable heart failure (New York Heart Association Class II-III) were randomized to 12 weeks of treatment with aliskiren $150 \mathrm{mg}$ or placebo in addition to prior treatment with an ACEI (or

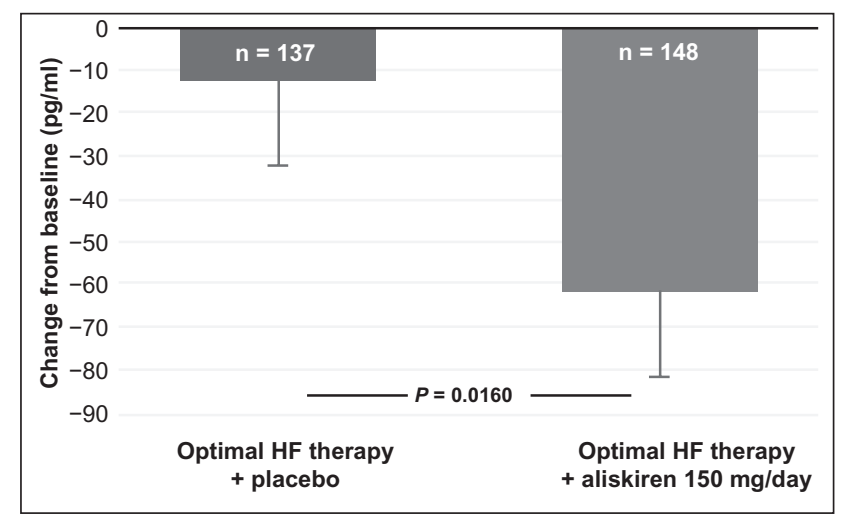

Figure 3 Primary end-point of the ALOFT study, change in plasma BNP from baseline to three months in aliskiren- or placebo-treated chronic heart failure (CHF) patients. Notes: Data presented as means \pm SEM.

Copyright (c) 2007, European Society of Cardiology. All rights reserved. Adapted with permission from Seed A, Gardner R, McMurray J, et al. Neurohumoral effects of the new orally active renin inhibitor, aliskiren, in chronic heart failure. Eur J Heart Fail. 2007;9: I I 20-1 I 27. ${ }^{52}$ 
ARB) and beta-blocker. Compared with placebo, aliskiren reduced plasma BNP by $25 \%(P=0.016)$, plasma $\mathrm{N}$-terminal proBNP by $25 \%(P=0.0106)$ and urinary aldosterone by $21 \%$ $(P=0.015)$. An improvement in Doppler echocardiographic measurement of left ventricular filling pressure was also observed. Aliskiren was well tolerated and there was no significant difference between aliskiren and placebo for the safety assessment of renal dysfunction, symptomatic hypotension, and hyperkalemia. Because reductions in BNP and plasma N-terminal proBNP with other RAAS inhibitors have been associated with improved cardiovascular outcomes in patients with heart failure, ${ }^{54}$ the neurohormonal results of ALOFT suggest that add-on treatment with aliskiren $150 \mathrm{mg}$ has the potential to reduce morbidity and mortality in these patients.

Left ventricular hypertrophy is a marker of cardiac end organ damage and is associated with increased cardiovascular morbidity and mortality. ${ }^{55}$ ALLAY (Aliskiren in Left Ventricular Hypertrophy) was a 36-week study that compared the effects of aliskiren $300 \mathrm{mg}$ and losartan $100 \mathrm{mg}$ alone and in combination on left ventricular hypertrophy (assessed by magnetic resonance imaging) in 465 overweight, hypertensive patients. ${ }^{32}$ Aliskiren monotherapy was statistically noninferior to losartan in reducing left ventricular mass index $\left(4.9 \mathrm{~g} / \mathrm{m}^{2}\right.$ for aliskiren versus $4.8 \mathrm{~g} / \mathrm{m}^{2}$ for losartan). The aliskiren-losartan combination resulted in a greater reduction in left ventricular mass index $\left(5.8 \mathrm{~g} / \mathrm{m}^{2}\right)$ compared with losartan monotherapy, although the difference was not statistically significant (Figure 4). These results were independent of BP decrease. Safety and tolerability were similar across all the treatment groups.

ASPIRE evaluated the effects of adding aliskiren to standard therapy, including an ACEI or an ARB, on left ventricular volume and function after myocardial infarction. ${ }^{39}$ A total of 820 post-myocardial infarction patients were randomly treated with aliskiren or placebo in addition to the best available medical therapy. At 36 weeks of follow-up, echocardiographically assessed left ventricular end-systolic volume (the primary outcome) was reduced by an average of $4.4 \mathrm{~mL}$ in the aliskiren group and by $3.5 \mathrm{~mL}$ in the placebo group (not statistically significant). No between-group differences were observed in left ventricular end-diastolic volume, infarct segment, or the percentage of patients whose ejection fraction decreased by more than six points. In addition, the

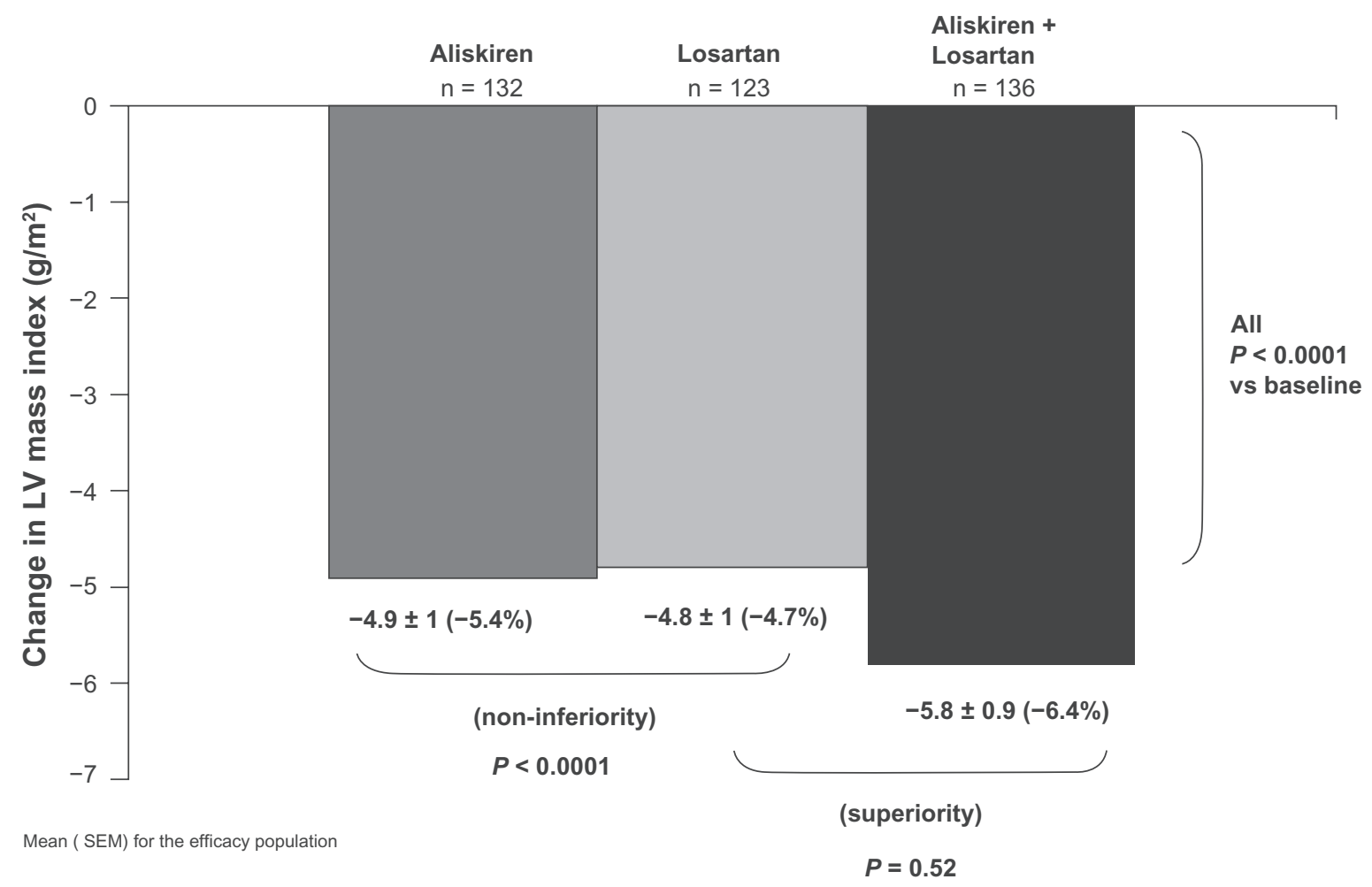

Figure 4 Primary efficacy analysis of the ALLAY Study. Comparison of left ventricular (LV) mass regression in patients receiving aliskiren, losartan or their combination. Bars show the mean \pm SEM for the efficacy population.

Copyright (C) 2009, Wolters Kluwer Health. Adapted with permission from Solomon SD, Appelbaum E, Manning WJ, et al; Aliskiren in Left Ventricular Hypertrophy (ALLAY) Trial Investigators. Effect of the direct renin inhibitor aliskiren, the angiotensin receptor blocker losartan, or both on left ventricular mass in patients with hypertension and left ventricular hypertrophy. Circulation. 2009; 1 19:530-537. ${ }^{32}$

Abbreviation: LV, left ventricular. 
combined rates for cardiovascular deaths, hospitalization for heart failure, recurrent heart attack, resuscitated sudden death, and stroke were similar between the aliskiren-treated patients and those given standard therapy. In contrast, patients receiving aliskiren in addition to another RAAS blocker had a higher rate of adverse events, particularly hyperkalemia and hypotension. The authors concluded that the use of this combination was not currently recommended following myocardial infarction.

The results of ASPIRE are consistent with those of ONTARGET (Ongoing Telmisartan Alone and in combination with Ramipril Global Endpoint Trial), ${ }^{56}$ which demonstrated no additional benefit in primary clinical outcomes among patients with vascular disease or high-risk diabetes receiving the combination of telmisartan-ramipril than outcomes in those treated with ramipril alone. Although combination therapy has a greater BP-lowering effect, dual RAAS blockade did not produce any significant clinical advantage in this high-risk population, but significantly increased the risk of hypotension, syncope, renal dysfunction, and hyperkalemia.

\section{Renal protection Experimental studies}

In hypertensive transgenic rats with diabetes, aliskiren was as effective as perindopril (an ACEI) in reducing albuminuria, fibrosis, and glomerulosclerosis but with a smaller antihypertensive effect, suggesting a more direct and prominent renal protective action. ${ }^{57}$ In the same animal model, Feldman et al confirmed the renal protective effect of aliskiren, and that aliskiren not only prevents the development of albuminuria but also suppresses production of transforming growth factor beta, a fibrosis-promoting cytokine. ${ }^{14}$ In this study, autoradiography enabled the investigators to localize aliskiren within the kidney and to assess the magnitude of renal partitioning. Aliskiren accumulated in renal tissue after two weeks of treatment and localized to the glomeruli and to the arterial walls of the small cortical blood vessels. These findings suggest that suppression of intrarenal RAAS may be at least one of the mechanisms contributing to the renal protection afforded by aliskiren.

\section{Clinical studies}

In a small clinical study ${ }^{58}$ conducted in 15 hypertensive patients with Type 2 diabetes and proteinuria, treatment with aliskiren $300 \mathrm{mg}$ daily for four weeks significantly reduced the urinary albumin:creatinine ratio as well as 24-hour ambulatory BP. The effect of aliskiren on decreasing albuminuria was observed within three days $(-17 \%)$ and reached a maximal effect $(-44 \%)$ within 28 days of treatment.

The first large study to assess the renoprotective effects of aliskiren was AVOID (Aliskiren in the Evaluation of Proteinuria in Diabetes), ${ }^{59}$ in which 599 patients with diabetes, nephropathy, and proteinuria were treated with losartan $100 \mathrm{mg}$ followed by the addition of placebo or aliskiren $300 \mathrm{mg}$. Adding aliskiren to losartan provided a further significant $20 \%$ reduction in urinary albumin:creatinine ratio compared with the addition of placebo. Almost twice as many patients in the aliskiren group achieved a reduction in urinary albumin:creatinine ratio of at least $50 \%$ from baseline. The additive antiproteinuric effect of combining aliskiren with losartan appeared to be independent of BP reduction, which was similar in the two treatment groups (Figure 5).

In a more recent study, Persson et a ${ }^{60}$ evaluated the renal effects of aliskiren $300 \mathrm{mg}$ or irbesartan $300 \mathrm{mg}$ alone and in combination in 26 hypertensive patients with Type 2 diabetes and albuminuria. Both monotherapies significantly reduced proteinuria, but the reduction was more pronounced with the aliskiren-irbesartan combination.

In salt-depleted healthy human subjects, dose-dependent increases in renal plasma flow following single-dose treatment with $75 \mathrm{mg}, 150 \mathrm{mg}$, and $300 \mathrm{mg}$ of aliskiren have been observed. ${ }^{61}$ The vasodilator response induced by aliskiren was twice that reported with ACEIs, and exceeded the effects of ARBs by about $40 \%$. Renal vasodilatation persisted for 48 hours after a single oral dose. The investigators postulated that the effects of aliskiren at the site of the RPR receptor may explain the marked renal vasodilator response.

\section{Vascular protection}

Experimental and clinical studies have demonstrated that RAAS blockade may reduce the development and progression of atherosclerotic lesions. For aliskiren, the most information comes from experimental studies, whereas few clinical data are available.

\section{Experimental studies}

In rats with renovascular hypertension, aliskiren was shown to be as effective as irbesartan in preventing progression of atherosclerosis. ${ }^{62}$ Interestingly, aliskiren increased smooth muscle cell content in atherosclerotic plaques significantly more than irbesartan, with consequent plaque stabilization. Furthermore, in Watanabe heritable hyperlipidemic rabbits, treatment with aliskiren significantly increased production of intra-aortic acetylcholine-induced nitric oxide, a surrogate index of endothelial protective function, and decreased 
A

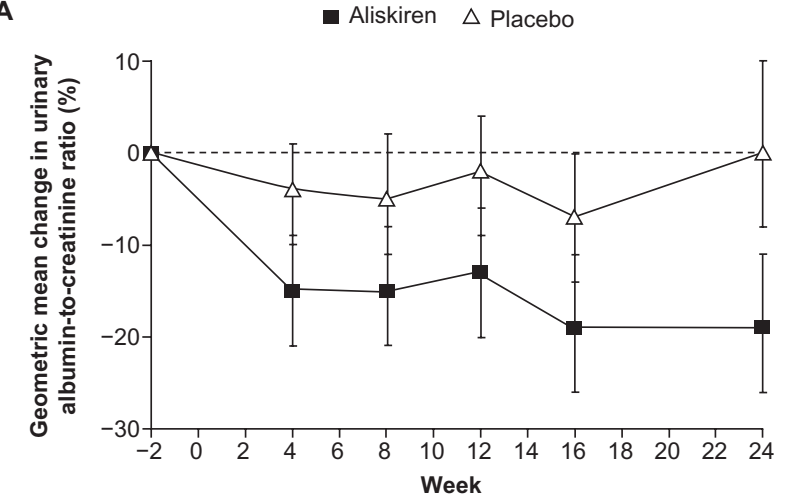

B

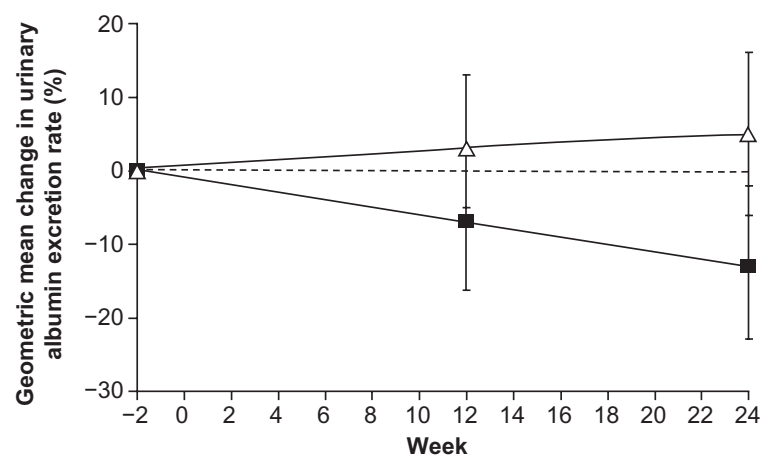

C

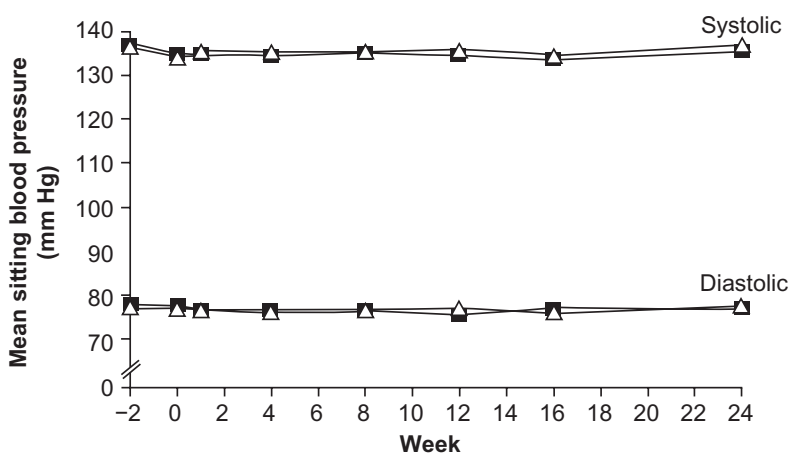

Figure 5 Changes from baseline ( 2 weeks before randomization) in the urinary albuminto-creatinine ratio (Panel A), urinary albumin excretion rate (Panel B) and mean sitting blood pressure (Panel C) according to Study Group in the AVOID Study.

Copyright () 2008, Massachusetts Medical Society. All rights reserved. Adapted with permission from Parving $\mathrm{HH}$, Persson $\mathrm{F}$, Lewis JB, Lewis EJ, Hollengerg $\mathrm{NH}$. Aliskiren combined with losartan in Type 2 diabetes and nephropathy. N Engl J Med. 2008;358:2433-2446. ${ }^{59}$

vascular superoxide and peroxynitrite levels. Furthermore, cotreatment with aliskiren and valsartan has additive protective effects on endothelial function and atherosclerotic changes. Histology of the thoracic aorta showed that the plaque area was significantly decreased by combination therapy compared with monotherapy with either drug. ${ }^{63}$

In a mouse model of obesity and Type 2 diabetes, Dong et $\mathrm{al}^{64}$ demonstrated that both subpressor and hypotensive doses of aliskiren significantly reduced cardiac fibrosis, macrophage infiltration, and coronary remodeling, and improved vascular endothelial function. These protective effects were attributed to the reduction of cardiac p22(phox)-related nicotinamide adenine dinucleotide phosphate oxidase-induced superoxide and the restoration of vascular endothelial nitric oxide synthase production. In order to investigate the effects of aliskiren on vascular inflammation, leukocyte adhesion assays were conducted in the mechanically-injured mouse femoral artery. ${ }^{65}$ The number of adherent leucocytes was significantly reduced in the injured mice treated with aliskiren. Furthermore, aliskiren significantly reduced the adhesion of THP-1 (T-helper precursor) cells to tumor necrosis factor-alpha-activated human umbilical vein endothelial cells and blunted tumor necrosis factor-alphainduced renin and Ang II production in these cells. These findings indicate that aliskiren has an anti-inflammatory effect.

\section{Clinical studies}

The only available data in humans are those from a recent pilot study that evaluated the effects of aliskiren $300 \mathrm{mg}$ daily on arterial stiffness and endothelial function in 10 patients with uncomplicated Type I diabetes mellitus during clamped euglycemia and hyperglycemia. In response to aliskiren, the carotid augmentation index decreased during clamped euglycemia as did pulse wave velocity during clamped hyperglycemia. ${ }^{66}$ In addition, endothelial-dependent vasodilation increased during both clamped euglycemia and hyperglycemia, as did endothelial-independent vasodilation (response to sublingual nitroglycerin).

In the ongoing AQUARIUS (Aliskiren Quantitative Atherosclerosis Regression Intravascular Ultrasound Study), intravascular ultrasonography will be used to assess the effects of aliskiren and placebo on atherosclerotic lesions in patients with coronary artery disease.

\section{Ongoing studies}

Several clinical trials are being carried out to evaluate the ability of aliskiren to prevent organ damage and reduce cardiovascular morbidity and mortality. ${ }^{48,67}$

In ALTITUDE (Aliskiren Trial In Type 2 Diabetes Using Cardio-Renal Endpoints), ${ }^{68} 8600$ high-risk diabetic patients will be randomly given aliskiren $300 \mathrm{mg}$ or placebo in addition to recommended doses of an ACE-I or ARB in order to assess time to first event of a combined renal/cardiovascular endpoint which includes cardiovascular death, stroke, myocardial infarction, and hospital admission for heart failure, in addition to the development of renal failure or doubling of serum creatinine.

ATMOSPHERE (Aliskiren Trial to Minimize Outcomes in Patients with Heart Failure) will assess whether aliskiren 
delays cardiovascular death or heart failure hospitalization in patients with chronic heart failure and systolic dysfunction (left ventricular ejection fraction $<40 \%$ ). Another study, ASTRONAUT (Aliskiren Trial on Acute Heart Failure Outcomes) is evaluating the effect of early initiation of aliskiren on death and recurrent hospitalization in the six months following hospital admission for decompensated heart failure. Meanwhile, APOLLO (Aliskiren in Prevention Of Later Life Outcomes) is assessing the effectiveness of aliskirenbased therapy in the primary and secondary prevention of cardiovascular morbidity and mortality in elderly patients with additional risk factors and with or without previous cardiovascular events. Finally, the AVANT-GARDE (aliskiren and valsartan to reduce NT-proBNP via renin-angiotensinaldosterone system blockade) study will assess whether aliskiren, alone or in combination with valsartan, improves ventricular hemodynamics, as assessed by reductions in NTproBNP levels in approximately 1100 patients.

\section{Conclusion}

In conclusion, the introduction of aliskiren, a direct renin inhibitor, into clinical practice has opened up a new therapeutic potential for hypertension and target organ protection. Aliskiren monotherapy displays an antihypertensive efficacy similar if not superior to that of other first-line antihypertensive drugs, with a safety and tolerability profile comparable with that of placebo, and also in special populations, including diabetic, obese, and elderly patients. Persistent BP reduction and prolonged suppression of PRA are observed after aliskiren withdrawal. Combining aliskiren with various antihypertensive agents results in greater antihypertensive efficacy without serious adverse drug interactions. Blockade of the RAAS obtained with ACEIs or ARBs can be further enhanced by adding aliskiren to these drugs. However, although improving BP control, the use of such a combination should be tempered by the results of ASPIRE, showing an increased incidence of adverse events at least in high-risk patients who have had a previous myocardial infarction. Data from experimental and clinical studies suggest that aliskiren is able to protect against end organ damage. The ongoing ASPIRE HIGHER clinical trial program, assessing the effects of aliskiren on surrogate markers and cardiovascular morbidity and mortality, will further define the role of direct renin inhibition in the available treatment options for hypertension.

\section{Disclosure}

The authors report no conflict of interest in this work.

\section{References}

1. Fyhrquist F, Saijonmaa O. Renin-angiotensin system revisited. J Intern Med. 2008;264:224-236.

2. Cesari M, Rossi GP, Pessina AC. Biological properties of the angiotensin peptides other than angiotensin II: Implications for hypertension and cardiovascular diseases. J Hypertens. 2002;20:793-799.

3. Dan Janser AH, Batenburg W, van Esch JH. Prorenin and the (pro)renin receptor - an update. Nephrol Dial Transplant. 2007;22:1288-1292.

4. Atlas SA. The renin-angiotensin-aldosterone system: Pathophysiological role and pharmacologic inhibition. J Manag Care Pharm. 2007;13 Suppl B:9-20.

5. Weber MA, Giles TD. Inhibiting the renin-angiotensin system to prevent cardiovascular disorders: Do we need a more comprehensive strategy? Rev Cardiovasc Med. 2006;7:45-54.

6. Abassi Z, Winaver J, Feuerstein GZ. The biochemical pharmacology of renin inhibitors: Implications for translational medicine in hypertension, diabetic nephropathy and heart failure: Expectations and reality. Biochem Pharmacol. 2009;78:933-940.

7. Jensen C, Herold P, Brunner HR. Aliskiren: The first renin inhibitor for clinical treatment. Nat Rev Drug Discov. 2008;7:399-410.

8. Wood JM, Maibaum J, Rahuel J, et al. Structure-based design of aliskiren, a novel orally effective renin inhibitor. Biophys Res Commun. 2003;308:698-705.

9. Rashid H. Direct renin inhibition:an evaluation of the safety and tolerability of aliskiren. Curr Med Res Opin. 2008;24:2627-2637.

10. Waldmeier F, Glaenzel U, Wirz B, et al. Absorption, distribution, metabolism and elimination of the direct renin inhibitor aliskiren in healthy volunteers. Drug Metab Dispos. 2007;35:1418-1428.

11. Zhao C, Vaidyanathan S, Yeh CM, et al. Aliskiren exhibits similar pharmacokinetics in healthy volunteers and patients with Type 2 diabetes mellitus. Clin Pharmacokinet. 2006;45:1125-1134.

12. Vaidyanathan S, Warren V, Yeh C, et al. Pharmacokinetics, safety and tolerability of the oral renin inhibitor aliskiren in patients with hepatic impairment. J Clin Pharmacol. 2007;47:192-200.

13. Sealey JE, Laragh JH. Aliskiren, the first renin inhibitor for treating hypertension: Reactive secretion may limit its effectiveness. $\mathrm{Am}$ J Hypertens. 2007;20:587-597.

14. Feldman DL, Jin L, Xuan H, et al. Effects of aliskiren on blood pressure, albuminuria and (pro)renin receptor expression in diabetic $\mathrm{TG}(\mathrm{mRen}-2)$ rats. Hypertension. 2008;52:130-136.

15. Gradman AH, Pinto R, Kad R. Current concepts: Renin inhibition in the treatment of hypertension. Curr Opin Pharmacol. 2008:8:120-126.

16. Menard J, Guyene TT, Peyrard S, Azizi M. Conformational changes in prorenin inhibition in vitro and in vivo. $J$ Hypertens. 2006;24:529-534.

17. Stanton A, Jensen C, Mann J, O'Brien E. Blood pressure lowering with SPP100, a novel orally active renin inhibitor: A pilot study. Hypertension. 2001;38:526.

18. Stanton A, Jensen C, Nussberger J, O'Brien E. Blood pressure lowering in essential hypertension with an oral renin inhibitor, aliskiren. Hypertension. 2003;42:1137-1143.

19. Gradman AH, Schiemer RE, Lins RL, Nussberger J, Chiang Y, Badigian MP. Aliskiren, a novel orally effective renin inhibitor, provides dose-dependent antihypertensive efficacy and placebo-like tolerability in hypertensive patients. Circulation. 2005;111:1012-1018.

20. Kushiro T, Itakuro H, Abo Y, et al. Aliskiren, a novel oral renin inhibitor, provides dose-dependent efficacy and placebo-like tolerability in Japanese patients with hypertension. Hypertens Res. 2006;29:997-1005.

21. Oh BH, Mitchell J, Herron JR, et al. Aliskiren, an oral renin inhibitor, provides dose-dependent efficacy and sustained 24-hour blood pressure control in patients with hypertension. $J$ Am Coll Cardiol. 2007;49:1157-1163.

22. Pool JL, Gradman A, Kolloch R, et al. Aliskiren, a novel renin inhibitor, provides long-term suppression of the renin system, when used alone or in combination with hydrochlorothiazide in the treatment of hypertension. Eur Heart J. 2006;27:119. 
23. Palatini P, Wung W, Shlyakhto E, Botha J, Bush C, Keefe DL. Maintenance of blood-pressure lowering effect following a missed dose of aliskiren, irbesartan or ramipril: Results of a randomized, doubleblind study. J Hum Hypertens. 2010;24:93-103.

24. Villamil A, Chrysant SG, Calhoun D, et al. Renin inhibition with aliskiren provides additive antihypertensive efficacy when used in combination with hydrochlorothiazide. J Hypertens. 2007;25: 217-226.

25. Schmieder RE, Philipp T, Guerediaga J, et al. Long-term antihypertensive efficacy and safety of the oral direct renin inhibitor aliskiren: A 12-month randomized, double-blind comparator trial with hydrochlorothiazide. Circulation. 2009;119:417-425.

26. Uresin Y, Taylor AA, Kilo C, et al. Efficacy and safety of the direct renin inhibitor aliskiren and ramipril alone or in combination in patients with diabetes and hypertension: J Renin Angiotensin Aldosterone Syst 2007;8:190-198.

27. Andersen K, Weinberger MH, Egan B, et al. Comparative efficacy and safety of aliskiren, an oral direct renin inhibitor, and ramipril in hypertension: A 6-month, randomized, double-blind trial. J Hypertens. 2008;26:589-599.

28. Duprez DA, Munger MA, Botha J, et al. Aliskiren for geriatric lowering of systolic hypertension: A randomized, controlled trial. J Hum Hypertens. Dec 24, 2009. [Epub ahead of print].

29. Strasser RH, Puig JG, Farsang C, et al. A comparison of the tolerability of the direct renin inhibitor aliskiren and lisinopril in patients with severe hypertension. J Hum Hypertens. 2007;21:780-787.

30. Oparil S, Yarows SA, Patel S, et al. Efficacy and safety of combined use of aliskiren and valsartan in patients with hypertension: A randomized, double-blind trial. Lancet. 2007;370:221-229.

31. Pool JL, Schmieder RE, Azizi M, et al. Aliskiren, an orally effective renin inhibitor, provides antihypertensive efficacy alone and in combination with valsartan. Am J Hypertens. 2007;20:11-20.

32. Solomon SD, Appelbaum E, Manning WJ, et al; Aliskiren in Left Ventricular Hypertrophy (ALLAY) Trial Investigators. Effect of the direct renin inhibitor aliskiren, the angiotensin receptor blocker losartan, or both on left ventricular mass in patients with hypertension and left ventricular hypertrophy. Circulation. 2009;119:530-537.

33. Drummond W, Munger MA, Rafique Essop M, et al. Antihypertensive efficacy of the oral direct renin inhibitor aliskiren as add-on therapy in patients not responding to amlodipine monotherapy. J Clin Hypertens. 2007;9:742-750.

34. Fogari R, Mugellini A, Preti P, et al. Effect of aliskiren addition to amlodipine on ankle oedema and subcutaneous tissue pressure in hypertensive patients. J Hypertens. 2010;28(e-Supp. A):PP 5.183 e 102.

35. Littlejohn TW 3rd, Trenkwalder P, Hollanders G, et al. Long-term safety, tolerability and efficacy of combination therapy with aliskiren and amlodipine in patients with hypertension. Curr Med Res Opin. 2009:25:951-959.

36. Taylor A, Tschope D, Kilo C, et al. Adding aliskiren to ramipril improves 24-hour blood pressure control compared to ramipril alone in patients with diabetes and hypertension. $J$ Hypertens. 2006;24 Suppl 4:81-82.

37. Yarrows SA, Oparil S, Patel S, et al. Aliskiren in combination with valsartan provides superior 24-hour ambulatory blood pressure reductions compared with either agent alone in patients with hypertension. J Clin Hypertens. 2007;9(5 Suppl A):188-189.

38. Weir M, Bush C, Anderson D, Zhang J, Keefe D, Satlin A. Antihypertensive efficacy, safety and tolerability of the oral direct renin inhibitor aliskiren in patients with hypertension: A pooled analysis. $J$ Am Soc Hypertens. 2007;1:264-277.

39. Solomon SD. Effect of the direct renin inhibitor aliskiren on left ventricular remodelling following myocardial infarction with left ventricular dysfunction: ASPIRE. Presented at: American College of Cardiology 59th Annual Scientific Sessions, Atlanta, GA: Mar 13-16, 2010.

40. Selby JV, Peng T, Karter AJ, et al. High rates of occurrence of hypertension, elevated low-density lipoprotein cholesterol and diabetes mellitus. Am J Manag Care. 2004;10:163-170.
41. Taylor AA, Anderson DR, Arora V, et al. Antihypertensive efficacy, safety and tolerability of the oral direct inhibitor aliskiren in patients with diabetes: A pooled analysis of 10 randomized trials. 67th Annual Scientific Session of ADA, Chicago, IL: Jun 22-26, 2007.

42. Bramlage P, Pittrow D, Wittchen HU, et al. Hypertension in overweight and obese primary care patients is highly prevalent and poorly controlled. Am J Hypertens. 2004;17:904-910.

43. Jordan J, Engeli S, Boye SW, Le Breton S, Keefe DL. Direct renin inhibition with aliskiren in obese patients with arterial hypertension. Hypertension. 2007;49:1047-1055.

44. Schmieder RE, Philipp T, Guerediaga J, Gorostidi M, Bush C, Keefe DL. Aliskiren-based therapy lowers blood pressure more effectively than hydrochlorothiazide-based therapy in obese patients with hypertension: Subanalysis of a 52-week, randomized, double-blind trial. J Hypertens. 2009;27:1493-1501.

45. Krone W, Hanefeld M, Meyer HF, et al. Comparative efficacy and safety of aliskiren and irbesartan in patients with metabolic syndrome. J Hum Hypertens. Apr 8, 2010. [Epub ahead of print].

46. Fogari R, et al. Different effects of aliskiren and losartan on fibrinolysis and insulin sensitivity in hypertensive patients with metabolic syndrome. Hormon. Metab. Res. 2010, in Press.

47. Verdecchia P, Calvo C, Mockel V, Keeling L, Satlin A. Safety and efficacy of the oral direct renin inhibitor aliskiren in elderly patients with hypertension. Blood Press. 2007;16:381-391.

48. ASPIRE HIGHER clinical program expands to 35,000 patients in 14 trials, the largest cardio-renal outcomes program ever. Available from: http://www.novartis.be/downloads/nl/pers-media/berichten/ reports/2008-07-17_financial-report_s1-2008_en.pdf. Accessed on Jun 25, 2010.

49. Pilz B, Shagdarsuren E, Wellner M, et al. Aliskiren, a human renin inhibitor, ameliorates cardiac and renal damage in double-transgenic rats. Hypertension. 2005;46:569-576.

50. Decherd R, Shagdarsren E, Gratze P, et al. Low-dose renin-inhibitor and low-dose AT1-receptor blocker therapy ameliorate target-organ damage in rats harbouring human renin and angiotensinogen genes. J Renin Angiotensin Aldosterone Syst. 2007:8:81-84.

51. Westermann D, Riad A, Lettau O, et al. Renin inhibition improves cardiac function and remodeling after myocardial infarction independent of blood pressure. Hypertension. 2008;52:1068-1075.

52. Seed A, Gardner R, McMurray J, et al. Neurohumoral effects of the new orally active renin inhibitor, aliskiren, in chronic heart failure. Eur J Heart Fail. 2007;9:1120-1127.

53. McMurray J, Pitt B, Latini R, et al. Effects of the oral direct renin inhibitor aliskiren in patients with symptomatic heart failure. Circ Heart Fail. $2008 ; 1: 17-24$

54. Latini R, Masson S, Anand I, et al. Effects of valsartan on circulating brain natriuretic peptide and norepinephrine in symptomatic chronic heart failure: The Valsartan Heart Failure Trial (Val-HeFT). Circulation. 2002;106:2454-2458.

55. Mancini GB, Dahlof B, Diez J. Surrogate markers for cardiovascular disease: Structural markers. Circulation. 2004;109:IV22-IV30.

56. The ONTARGET Investigators. Telmisartan, ramipril or both in patients at high risk for vascular events. New Engl J Med. 2008;358:1547-1559.

57. Kelly DJ, Zhang Y, Moe G, Naik G, Gilbert RE. Aliskiren, a novel renin inhibitor, is renoprotective in a model of advanced diabetic nephropathy in rats. Diabetologia. 2007;50:2398-2404.

58. Persson F, Rossing P, Schjoedt KJ, et al. Time course of the antiproteinuric and antihypertensive effects of direct renin inhibition in Type 2 diabetes. Kidney Int. 2008;73:1419-1425.

59. Parving HH, Persson F, Lewis JB, Lewis EJ, Hollengerg NH. Aliskiren combined with losartan in Type 2 diabetes and nephropathy. $N$ Engl $J$ Med. 2008;358:2433-2446.

60. Persson F, Rossing P, Reinhard H, et al. Renal effects of aliskiren compared with and in combination with irbesartan in patients with Type 2 diabetes, hypertension and albuminuria. Diabetes Care. 2009;32:1873-1879. 
61. Fischer ND, JanDanser AH, Nussberger J, Dole WP, Hollenberg NK. Renal and hormonal responses to direct renin inhibition with aliskiren in healthy humans. Circulation. 2008;117:3199-3205.

62. Nussberger J, Aubert JF, Bouzourene K, Pellegrin M, Hayoz D, Mazzolai L. Renin inhibition by aliskiren prevents atherosclerosis progression: Comparison with irbesartan, atenolol, and amlodipine. Hypertension. 2008;51:1306-1311.

63. Imanishi $\mathrm{T}$, Tsujioka $\mathrm{H}$, Ikejima $\mathrm{H}$, et al. Renin inhibitor aliskiren improves impaired nitric oxide bioavailability and protects against atherosclerotic changes. Hypertension. 2008;52:563-572.

64. Dong YF, Liu L, Kataoka K, et al. Aliskiren prevents cardiovascular complications and pancreatic injury in a mouse model of obesity and Type 2 diabetes. Diabetologia. 2010;53:180-191.

65. Ino J, Kojima C, Osaka M, Nitta K, Yoshida M. Dynamic observation of mechanically-injured mouse femoral artery reveals an antiinflammatory effect of renin inhibitor. Arterioscler Thromb Vasc Biol. 2009;29:1858-1863.
66. Cherney DZ, Lai V, Scholey JW, Miller JA, Zinman B, Reich HN. The effect of direct renin inhibition on renal haemodynamic function, arterial stiffness and endothelial function in humans with uncomplicated Type 1 diabetes mellitus: A pilot study. Diabetes Care. 2010;33:361-365.

67. Sever PS, Gradman AH, Azizi M. Managing cardiovascular and renal risk: The potential of direct renin inhibition. J Renin Angiotensin Aldosterone Syst. 2009;10:65-76.

68. Parving HH, Brenner BM, McMurray JJ, et al. Aliskiren Trial in Type 2 Diabetes Using Cardio-Renal Endpoints (ALTITUDE): Rationale and study design. Nephrol Dial Transplant. 2009;24:1663-1671.

\section{Publish your work in this journal}

Vascular Health and Risk Management is an international, peerreviewed journal of therapeutics and risk management, focusing on concise rapid reporting of clinical studies on the processes involved in the maintenance of vascular health; the monitoring, prevention and treatment of vascular disease and its sequelae; and the involvement of metabolic disorders, particularly diabetes. This journal is indexed on PubMed Central and MedLine. The manuscript management system is completely online and includes a very quick and fair peer-review system, which is all easy to use. Visit http://www.dovepress.com/ testimonials.php to read real quotes from published authors. 